Check for updates

Cite this: RSC Adv., 2017, 7, 27846

Received 1st February 2017

Accepted 19th May 2017

DOI: 10.1039/c7ra01327b

rsc.li/rsc-advances

\section{Study on electro-kinetic remediation of heavy metals in municipal solid waste incineration fly ash with a three-dimensional electrode}

\author{
Yuewei Zhang, $\uparrow^{a}$ Tao Huang, $\uparrow^{a}$ Xiao Huang, $\uparrow^{a}$ Muhammad Faheem, $\uparrow^{a}$ Lin $Y u, \dagger^{a b}$ \\ Binquan Jiao, ${ }^{* a b}$ Guangzhi Yin, ${ }^{* a}$ YanChyuan Shiau*c and Dongwei Li (iD) *a
}

\begin{abstract}
Fly ash from incinerated municipal solid waste is a source of secondary pollutants ( $\mathrm{Cu}, \mathrm{Zn}, \mathrm{Pb}$ and $\mathrm{Cd})$. The inappropriate management of fly ash leads to the contamination of soil and ground water. This paper is based on the electro-kinetic removal of heavy metals from municipal solid waste incinerated fly ash by using a three-dimensional electrode in orthogonal single and multi-factor experiments to obtain the optimal experimental conditions by varying the leaching toxicity removal rate for the heavy metals in the groups. The optimal dimensions $(6 \times 6 \mathrm{~mm})$ of the particle electrodes to achieve high removal rates for heavy metals are found by using various measurements in single-factor orthogonal experiments. In addition, the multi-factor orthogonal experiment is based on three factors: (a) the particle electrode ratio, (b) the voltage gradient and (c) the repair time, while keeping the optimum specification $(6 \times 6$ $\mathrm{mm}$ ) for particle electrodes constant. The result showed that a high removal rate for heavy metals was obtained by applying a voltage gradient of $9 \mathrm{~V}$ for 5 days (repair time) and a $5 \%$ dosing ratio.
\end{abstract}

\section{A Introduction}

In recent years, the handling of a large volume of municipal solid waste has been a great challenge due to the rapid growth of urbanization. There are several methods to dispose of waste including sanitary, incineration and composting. Incineration is one of the most important disposal methods due to the easy selection of a site to treat a large volume of waste while utilizing less space and time. Moreover, because it has less weight $(70 \%)$ and reduced volume $(90 \%)$, the disposed material is harmless. ${ }^{1-8}$

In recent years, hundreds of waste incinerator plants have been working or are under construction in China, with a processing capacity of 50000 tons per day. ${ }^{9,10}$ The improper disposal and purification of solid residues and flue gas (containing a high content of heavy metals) may cause secondary pollution in the environment. ${ }^{11,12}$ These secondary pollutants consist predominantly of copper $(\mathrm{Cu})$, zinc $(\mathrm{Zn})$, cadmium $(\mathrm{Cd})$ and lead $(\mathrm{Pb})$. They escape into the environment, causing ground water pollution by infiltration and the runoff of rainfall,

\footnotetext{
${ }^{a}$ State Key Laboratory for Coal Mine Disaster Dynamics and Control, Chongqing University, Chongqing 400044, P. R. China.E-mail: j.binquan@cqu.edu.cn; gzyin@ cqu.edu.cn; litonwei@cqu.edu.cn

${ }^{b}$ City College of Science and Technology, Chongqing University, Chongqing, 400044, China

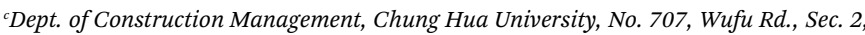
Hsinchu 30012, Taiwan.E-mail: ycshiau@chu.edu.tw

$\dagger$ These authors contributed equally to the work.
}

and ultimately affect human beings. Therefore, proper disposal of fly ash is necessary to prevent secondary pollution.

Another technology known as electro-kinetic, is used to remove contaminants from soil. This technology is based on electrodes. Metal ions migrate towards the corresponding electrodes, according to their charge to achieve the recovery of metals. ${ }^{13-15}$ Later, this technology was implemented in fly ash treatment for the removal of heavy metals, and it involves three stages: (1) the electrolysis of water in the sample area results in changing basic solution to acidic; (2) under acidic conditions, heavy metals in fly ash dissolve out; and (3) electro-kinetic technology is used to remove the heavy metals from the sample area. ${ }^{9}$

The three-dimensional electrode method ${ }^{16}$ is a new type of electro-chemical treatment technology. The traditional twodimensional electrolytic cell transforms into a third electrode after filling granular or other fragmental particles. The specific surface area of three-dimensional electrodes is greater than that of two dimensional electrodes. A high specific surface area increases mass the transfer effect and ultimately increases the transfer rate. In addition, three-dimensional electrodes increase the current efficiency and space time yield, and they buffer the sample $\mathrm{pH} .{ }^{17-20}$

The three-dimensional electrode method has mainly been used for waste water treatment worldwide. Zhang Shaofeng et al. studied the current methods for analysing the various factors that influence the removal rate of $\mathrm{Pb}$ in low acidic industrial wastewater. ${ }^{21}$ These results present that the removal rate of heavy metals can reach up to $34 \%$ by using three- 
dimensional electrodes with a stainless steel cathode. Additionally, Hao Xuekui et al. stated that compared to the two directional electrode method, the current method has an enhanced removal rate of copper ions up to $38 \%$ in dilute acidic solution because the energy requirement is reduced to $20 \%{ }^{22}$ Gui fen Lv et al. used carbon air-gel instead of activated carbon (which is conventionally used) as a particle electrode in a threedimensional electrode system to treat waste water in the presence of phenol, which stimulates the chemical reaction. ${ }^{23}$ The results show that the new particle electrode (carbon air-gel) had a stronger effect and remained active for a longer time than to conventional one. As a new electrochemical technology, the three-dimensional electrode has been widely applied to remove heavy metals or organic substances from waste water. A number of researchers have also worked on desulfurization for flue gas treatment. ${ }^{24}$ However, limited research has been conducted on the removal of heavy metals from solid waste.

A number of factors affects the electro-kinetic techniques implemented for treating fly ash including the composition of the fly ash, the behaviour of heavy metals present in the fly ash and electro-kinetic experimental conditions.

The present experiment examined (a) the influence of various experimental conditions on the removal efficiency of heavy metals from fly ash, (b) ways to achieve optimum experimental conditions for the three dimensional electrode technique based on removal rate, repair time and voltage gradient, and (c) a design for a set of single and multi-factor orthogonal experiment. The present experiment obtained the optimal conditions for three-dimensional electrode systems by using a single treatment that requires a specific particle electrode, particle electrode concentration ratio, voltage gradient between electrodes, and repair time to be chosen as the main design indices. In addition, an experiment was designed for the leaching of heavy metals, which is an indication of heavy metals removal.

\section{B Methods and experiments}

\section{a Materials}

The fly ash samples were taken from a municipal waste incineration furnace in Chongqing. The fly ash samples were dried by heating at $105^{\circ} \mathrm{C}$ for $24 \mathrm{~h}$ and were sieved through 200-mesh (75 microns) to remove large particles.

The water used in the electric experiment is tap water. The chemical composition is shown in Table 1 , which is derived

Table 1 The chemical composition of tap water ${ }^{a}$

\begin{tabular}{llll}
\hline Item & Values & Item & Values \\
\hline $\mathrm{pH}$ & $6.5-8.5$ & $\mathrm{As}\left(\mathrm{mg} \mathrm{L}^{-1}\right)$ & - \\
$\mathrm{Fe}\left(\mathrm{mg} \mathrm{L}^{-1}\right)$ & $<0.02$ & $\mathrm{Se}\left(\mathrm{mg} \mathrm{L}^{-1}\right)$ & $<0.002$ \\
$\mathrm{Cu}\left(\mathrm{mg} \mathrm{L}^{-1}\right)$ & $<0.005$ & $\mathrm{Hg}\left(\mathrm{mg} \mathrm{L}^{-1}\right)$ & $<0.0001$ \\
$\mathrm{Zn}\left(\mathrm{mg} \mathrm{L}^{-1}\right)$ & $<0.02$ & $\mathrm{Cd}\left({\left.\mathrm{mg} / \mathrm{L}^{-1}\right)}^{-1}\right.$ & - \\
$\mathrm{NO}_{3}^{-1}\left(\mathrm{mg} \mathrm{L}^{-1}\right)$ & 1.68 & $\mathrm{Cr}(\mathrm{vI})\left(\mathrm{mg} \mathrm{L}^{-1}\right)$ & - \\
$\mathrm{Cl}^{-}\left(\mathrm{mg} \mathrm{L}^{-1}\right)$ & 0.95 & $\mathrm{~Pb}\left(\mathrm{mg} \mathrm{L}^{-1}\right)$ & $<0.007$ \\
$\mathrm{~F}^{-}\left(\mathrm{mg} \mathrm{L}^{-1}\right)$ & 0.21 & $\mathrm{Ag}\left(\mathrm{mg} \mathrm{L}^{-1}\right)$ & - \\
$a-$ means that it is not detected. & &
\end{tabular}

from Chongqing Water Supply Co., Ltd. The water used in the leaching experiment was an acetic acid solution with a $\mathrm{pH}$ of 2.64, that was prepared according to the Solid Waste Leaching Toxicity Leaching Method - Acetate Buffer Solution (HJ/T3002007).

(a) The analysis of the total content of heavy metals in fly ash. The samples were digested by using the microwave digestion method to analyse the total amount of heavy metals in MSWI fly ash. They were digested in a mixture of $\mathrm{HNO}_{3^{-}}$ : $\mathrm{HF}: \mathrm{H}_{2} \mathrm{O}_{2}=5: 4: 1$. Three samples (each of $0.5 \mathrm{~g}$ ) of dried $\left(110{ }^{\circ} \mathrm{C}\right)$ fly ash were digested in the digestion mixture. The results are given in Table 2 .

As seen from Table 2, the content of $\mathrm{Cu}, \mathrm{Zn}, \mathrm{Pb}$ and $\mathrm{Cd}$ in the fly ash exceeded the soil environmental residential land secondary standards (GB15618-2008). The average $\mathrm{Zn}$ and $\mathrm{Pb}$ contents were 11.2 and 6.1 times greater than the secondary standards (GB15618-2008), respectively. Although the $\mathrm{Cu}$ and $\mathrm{Cd}$ concentrations were relatively low compared to $\mathrm{Zn}$ and $\mathrm{Pb}$, they still exceeded the soil environmental residential land secondary standards (GB15618-2008).

(b) The XRF analysis of fly ash. The results in Table 3 show that the incinerated fly ash of MSW mainly contained $\mathrm{O}, \mathrm{Ca}, \mathrm{Cl}$, $\mathrm{Na}, \mathrm{K}, \mathrm{S}, \mathrm{Si}$ and other elements in trace amounts. Furthermore, it can be observed that heavy metals (e.g., $\mathrm{Cu}, \mathrm{Zn}, \mathrm{Pb}, \mathrm{Cr}, \mathrm{Mn}$ ) occurred in trace amounts, and were most closely integrated with silicate, and silicon aluminates. The resulting analyses of heavy metals may vary depending on the different methodologies and latest technologies. The XRF results show that $\mathrm{Zn}$ was in the highest concentration followed by $\mathrm{Pb}$ and $\mathrm{Cu}$. But $\mathrm{Cd}$ is also present in a high concentration, as shown in Table 2. These heavy metals are harmful for the environment. Therefore, the present study is based on the heavy metals $\mathrm{Cu}, \mathrm{Zn}, \mathrm{Pb}$ and $\mathrm{Cd}$.

\section{b The experimental device}

The electro-kinetics removal experiment was conducted in a small glass chamber, with the sample region having dimensions of $8 \times 8 \mathrm{~cm}$. The most commonly used particle electrodes are activated carbon and graphite. The experiment was greatly affected by the nature and concentration of the particle electrode. In this experiment, the graphite electrode served as a particle electrode instead of activated carbon. A high EC may result in a short circuit and reduce the experimental reliability.

Table 2 Total content of heavy metals in MWSI fly ash $\left(\mathrm{mg} \mathrm{kg}^{-1}\right)$

\begin{tabular}{lcccr}
\hline The fly ash sample number & $\mathrm{Cu}$ & $\mathrm{Zn}$ & $\mathrm{Pb}$ & $\mathrm{Cd}$ \\
\hline 1 & 741 & 5800 & 1820 & 326 \\
2 & 678 & 5638 & 1716 & 324 \\
3 & 655 & 5374 & 1930 & 312 \\
Average value & 691 & 5604 & 1822 & 321 \\
GB15618-2008II & 300 & 500 & 300 & 10 \\
Average value $a$ & 2.3 & 11.2 & 6.1 & 3.2 \\
GB15618-2008II & & & & \\
a GB15618-2008II & is soil environmental & residential land secondary \\
standards (draft). & & & &
\end{tabular}


Table 3 Elements of the raw MSWI fly ashes (\%)

\begin{tabular}{llllllllll}
\hline $\mathrm{Ca}$ & $\mathrm{O}$ & $\mathrm{Cl}$ & $\mathrm{Na}$ & $\mathrm{K}$ & $\mathrm{Si}$ & $\mathrm{S}$ & $\mathrm{Mg}$ & $\mathrm{Fe}$ & $\mathrm{Al}$ \\
\hline 37.50 & 26.76 & 17.44 & 4.32 & 3.47 & 2.80 & 1.99 & 1.50 & 1.05 & 1.02 \\
\hline $\mathrm{Zn}$ & $\mathrm{P}$ & $\mathrm{Ti}$ & $\mathrm{Pb}$ & $\mathrm{Br}$ & $\mathrm{Cr}$ & $\mathrm{Sr}$ & $\mathrm{Ba}$ & $\mathrm{Cu}$ & $\mathrm{Mn}$ \\
\hline 0.68 & 0.40 & 0.30 & 0.25 & 0.14 & 0.09 & 0.08 & 0.08 & 0.08 & 0.05 \\
\hline
\end{tabular}

Fly ash (150 g) was mixed with different mass percentages of graphite particle electrodes and placed into the experimental sample region, in which the level of water was high compared to the content of fly ash. A stain less steel cathode and graphite anode were connected to the main power supply via aluminum wire (Fig. 1). The parameters were adjusted according to the single factor orthogonal experiment.

\section{c The design of the experiment}

Based on other literature, which considered the removal rate and the unit energy consumption, the single factor experiment was designed with the graphite particle electrode (A1-A5 in Table 4) as the variable factor. The other three invariant factors were as follows: the particle electrode ratio was $10 \%$, the voltage was $4.5 \mathrm{~V}$, and the repair time was 5 days with three parallel experiments.

The optimal experimental conditions for particle electrode specifications obtained by the single-factor experiment were used in the orthogonal experiment. The $\mathrm{L}_{9}\left(3^{4}\right)$ orthogonal table (as shown in Table 5) was designed with three factors, the particle electrode ratio, the voltage gradient and repair time.

\section{d The calculation of the results}

The design of the experiment was made in such a way that the sample region was divided into three sections (as shown in Fig. 1): T1 (near the cathode channel), T2 (middle area) and T3 (near the anode tank). The fly ash samples were used for further analysis. Leaching toxicity was measured by the "Solid Waste method for leaching toxicity-acetic acid buffer solution method" (HJ/T300-2007). An atomic absorption spectrophotometer (AAS) was used to determine the concentration of copper, zinc, lead and cadmium from the leachate.

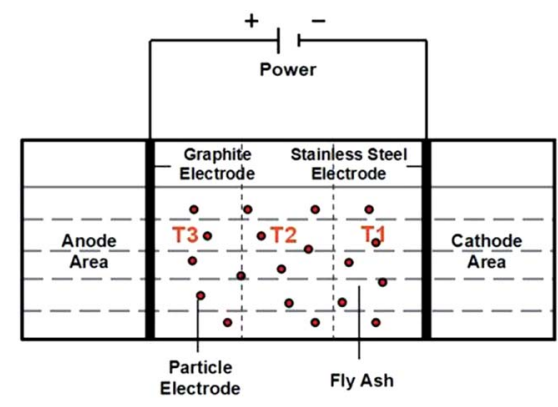

Fig. 1 The experimental device schematic diagram.
The heavy metal leaching toxicity removal rate was the ratio of leaching toxicity difference of the fly ash (before and after electro-kinetics removal) and the leaching toxicity of fly ash before the electro-kinetic removal. The mathematical expression is:

$$
y=\frac{U_{0}-U}{U_{0}} \times 100 \%
$$

where, the removal rate for heavy metals leaching toxicity was represented by $y . U_{0}$ represented the leaching toxicity of fly ash heavy metal before electro-kinetics removal and the toxicity after electro-kinetics removal was noted by $U$.

\section{e Leaching tests}

A leaching toxicity test that referred to the Chinese standard $\mathrm{HJ} /$ T299-2007-"The leaching toxicity of solid waste-acetic acid buffer solution method" was done for the solidified samples. The pulverized sample particles ranging from 4.75 to $9.50 \mathrm{~mm}$ were sieved and mixed with prepared chemical reagents (glacial acetic acid solution) at a ratio of $20: 1$ (liquid/mass, $\mathrm{mL} \mathrm{g}^{-1}$ ). The mixture was shaken on an oscillating device at the speed of $30 \pm 2 \mathrm{rpm}$ for $18 \pm 2 \mathrm{~h}$ and kept at a constant temperature of 23 $\pm 2{ }^{\circ} \mathrm{C}$. The leachate from the samples was filtered through a microporous filter membrane $(\Phi 0.8 \mu \mathrm{m})$ and the concentration of heavy metal ions ( $\mathrm{Zn}, \mathrm{Pb}, \mathrm{Cu}$ and $\mathrm{Cd}$ ) were detected using an atomic absorption spectrophotometer (AAS).

\section{Results and discussion}

\section{a Macro phenomenon}

After pretreatment (sieving and drying), the $\mathrm{pH}$ of the samples was recorded every 12 hours in both the single and multi-factor orthogonal experiments. Basically the experimental phenomena were the same in both experiments:

(1) A bubbling phenomenon with emission of a pungent odour was observed in the cathode and anode electrode regions as the power was supplied. This phenomenon occurred due to presence of $\mathrm{Cl}^{-}$ions in the fly ash sample and water.

Cathodic reaction:

$$
2 \mathrm{H}_{2} \mathrm{O}+2 \mathrm{e}^{-} \rightarrow 2 \mathrm{OH}^{-}+\mathrm{H}_{2} \uparrow
$$

Anodic reaction:

$$
\begin{gathered}
\mathrm{H}_{2} \mathrm{O}-2 \mathrm{e}^{-} \rightarrow 2 \mathrm{H}^{+}+1 / 2 \mathrm{O}_{2} \uparrow \\
2 \mathrm{Cl}^{-}-2 \mathrm{e}^{-} \rightarrow \mathrm{Cl}_{2} \uparrow
\end{gathered}
$$

(2) During the experiment, the fly ash within the sample area gradually became compacted and hardened.

(3) As shown in Fig. 2, white precipitates of the metals were observed at the cathode electrode due to the presence of $\mathrm{OH}^{-}$ ions in the alkali environment. There was no precipitation on the anode electrode because of $\mathrm{H}^{+}$ions in the acidic environment. 
Table 4 Analysis of variance results table ${ }^{a}$

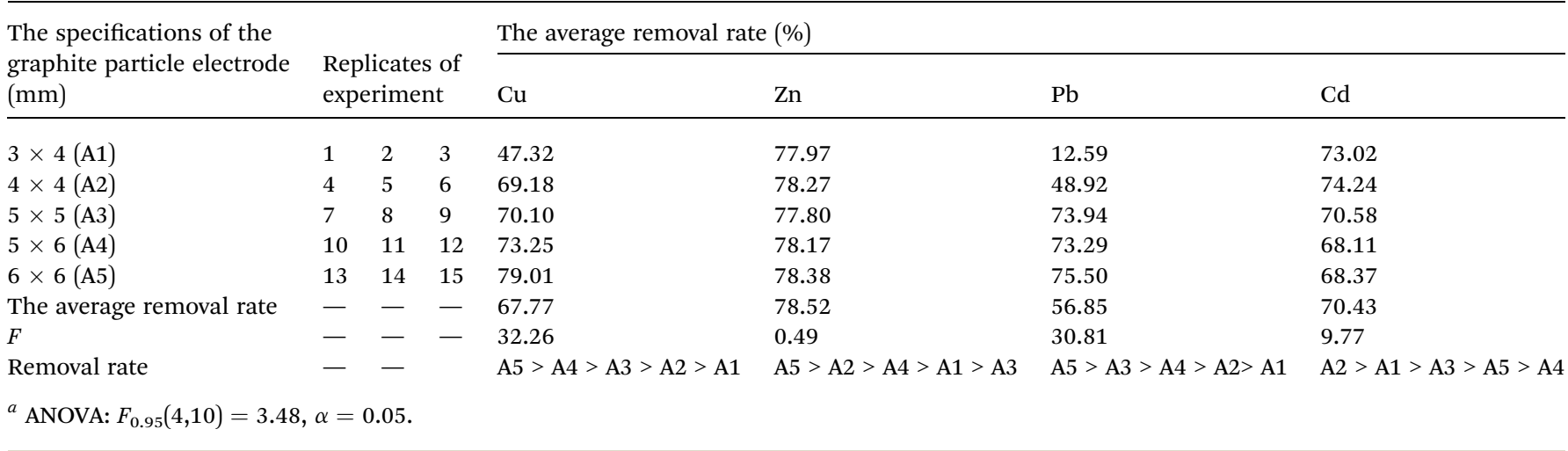

\section{b The single factor experiment}

(a) The change of the current systems over time. Fig. 3 shows the change of the current versus time of removal of the heavy metals from five groups (Table 4) in the single factor electro-kinetic removal experiment system. The current in the system was related to the quantity of electro-kinetics charge moving through the sample region in a unit time. As seen from Fig. 3, the initial current was nearly the same for all five groups. It was noted that the current gradually decreased for two reasons: first, heavy metals and other cations migrated towards the cathode during the electro-kinetic removal process. Among these cations; some maintained their ionic state, but others precipitated in the alkaline environment, and were attached to the cathode. This caused an increase in resistance and hence, the current was reduced. ${ }^{25}$ The second reason is that precipitated cations were attached to fly ash by reducing the gap between them, near the walls of the glass where the cathode is grooved. This lead to an increase in the resistance (by a reduction in the concentration of free ion) of the sample area, consequently, the current was reduced.

(b) The change of $\mathbf{p H}$ over time. The $\mathrm{pH}$ variations over time at the cathode and anode influenced regions are shown in Fig. 4 for the single-factor experiment (for five groups). Later, $\mathrm{pH}$ was decreased to approximately 10 . Although the variation of $\mathrm{pH}$ was not significantly obvious around the anode zone, it was concluded that with the passage of time, a decrease in

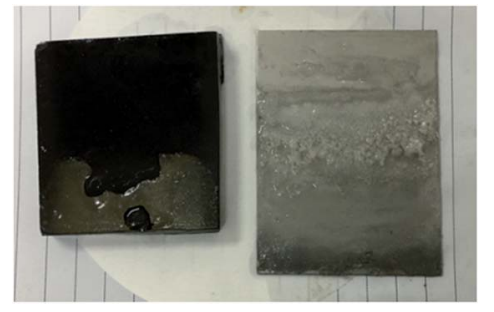

Fig. 2 Anode and cathode electrode after experiment.

current and a reduction of $\mathrm{OH}^{-}$, the $\mathrm{pH}$ decreased in the cathode influenced area.

(c) The analysis of the removal results. The current experiment was categorized into five groups (A1, A2, A3, A4 and A5) based on different specifications/dimensions of the graphite particle electrodes while keeping the other three factors constant: the particle dose ratio (10\%), voltage ( $4.5 \mathrm{~V}$ ) and repair time (5 days) in all groups. The experimental lay out and average removal rate for $\mathrm{Cu}, \mathrm{Zn}, \mathrm{Pb}$ and $\mathrm{Cd}$ with $\mathrm{F}$ ratios is shown in Table 4. ANOVA (Analysis of Variance) was performed to achieve the optimum level among the five dimensions.

The removal rate for the five groups is shown in Table 4. It was noted from the results that the $\mathrm{Cu}, \mathrm{Pb}$ and $\mathrm{Cd}$ removal rates were significantly affected in all groups. Although the four kinds of particle sizes had no effect on Zn removal, the maximum removal rate for $\mathrm{Cu}$ and $\mathrm{Pb}$ was observed in $\mathrm{A} 5$, with

Table 5 Orthogonal experiments

\begin{tabular}{|c|c|c|c|c|c|c|c|}
\hline No. S- & $\begin{array}{l}\text { Particle electrode } \\
\text { ratio (A) }\end{array}$ & $\begin{array}{l}\text { Voltage gradient } \\
\text { (B) }\end{array}$ & Repair time (C) & \multicolumn{4}{|c|}{ Removal rate (\%) } \\
\hline S2 & $2(10 \%)$ & 1 & 2 (10 days) & 33.73 & 3.93 & 17 & 1.99 \\
\hline S3 & $3(15 \%)$ & 1 & 3 (15 days) & 12.06 & 7.02 & 17.52 & 14.10 \\
\hline S4 & 1 & $2(9 \mathrm{~V})$ & 2 & 37.59 & 10.05 & 24.17 & 17.86 \\
\hline S7 & 1 & $3(18 \mathrm{~V})$ & 3 & 11.92 & 6.69 & 3.46 & 4.65 \\
\hline S8 & 2 & 3 & 1 & 79.7 & 76.23 & 32.34 & 69.00 \\
\hline S9 & 3 & 3 & 2 & 12.92 & 8.58 & 11.17 & 7.88 \\
\hline
\end{tabular}




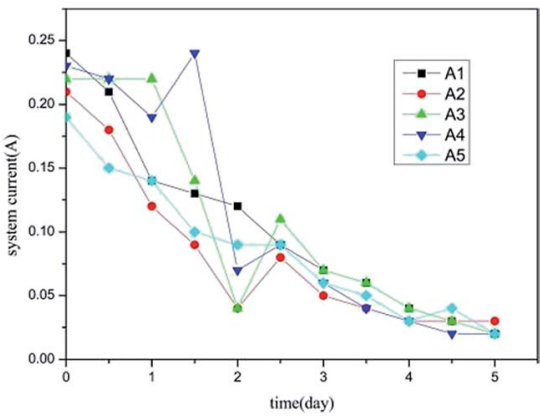

Fig. 3 The single factor experiment current change.

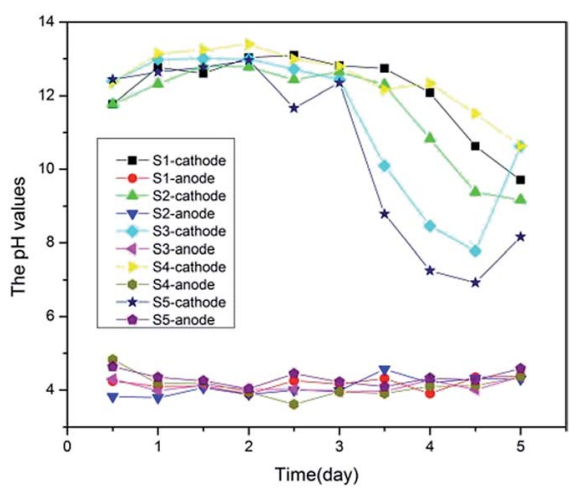

Fig. 4 The $\mathrm{pH}$ variation of the single factor experiment.

a dimension of $6 \times 6 \mathrm{~mm}$; in case of $\mathrm{Cd}$, it was observed for A2 $(4 \times 4 \mathrm{~mm})$. The decreasing orders of removal rate are presented in Table 4. The particle contact points increased due to the increasing specific surface area of the particle electrodes, resulting in resistance between particles decreasing and current flow increasing. The results indicate that particle electrode with dimension of $6 \times 6 \mathrm{~mm}$ were optimum.

\section{c The multifactor experiment}

(a) The change of the current systems over time. The nine experiments were conducted by using three factors at different values: the particle electrode ratio (A), voltage gradient (B) and repair time (C). In addition, each factor was replicated three times in different combinations, as seen in Table 5. The change in current with respect to time for the multifactor electro-kinetic removal orthogonal experiment is shown in Fig. 5. It can be seen that the initial current was huge for the experiments provided with a high voltage gradient compared with a low voltage gradient i.e., $\mathrm{V} 3(\mathrm{~S} 7, \mathrm{~S} 8, \mathrm{~S} 9)>\mathrm{V} 2(\mathrm{~S} 4, \mathrm{~S} 5, \mathrm{~S} 6)>\mathrm{V} 1(\mathrm{~S} 1, \mathrm{~S} 2, \mathrm{~S} 3)$. Among these three groups of voltage gradient, S1, S4 and S8 had a higher initial current than did the other two experimental replicates from their respective groups (A1, A2, and A3, respectively). It was due to the different ratios of the graphite particle electrode. In the three-dimensional electrode system, the electro-kinetic field between the cathode and anode electrodes polarized the graphite particles, and the charged particles migrated to their respective poles. With the migration of

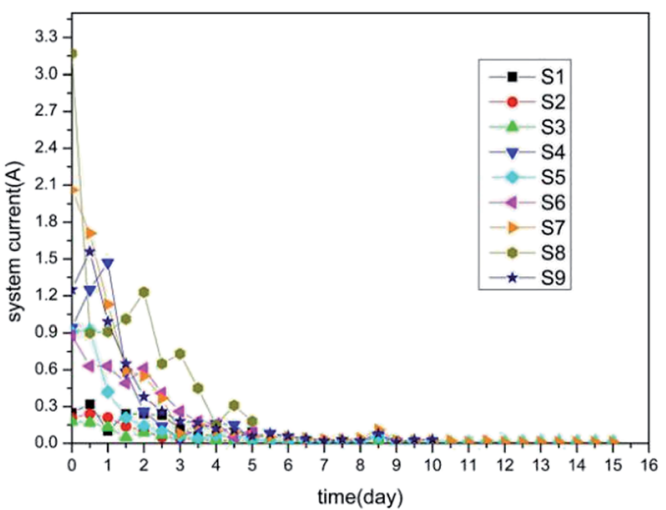

Fig. 5 The multifactor experiment current change.

the particles, the oxidation and reduction of ions occurred at the anode and cathode respectively. Moreover the space between particles had a great influence on the change in current. ${ }^{26} \mathrm{~A}$ decrease in the electro-kinetic current was observed with the passage of time. This occurred was due to the production of $\mathrm{OH}^{-}$during the electrolysis of water, which resulted in the precipitation of ions.

(b) The analysis of the removal results. The optimal dimensions for particle electrode were achieved on the basis of a single-factor orthogonal experiment and they were used for the multifactor orthogonal experiment. The layout of an orthogonal experiment $\mathrm{L}_{9}\left(3^{4}\right)$ is presented in Table 5. Nine groups were carried out each with three replicates $(9 \times 3=27)$. Later the sample area was divided in to three parts with the help of stainless steel to get three samples (T1, T2, T3) for heavy metals removal analysis from each group; thus, the total was 81 $(9 \times 3=27 \times 3=81)$ samples. The average removal rates for heavy metals were determined by using eqn (1), and the range analysis results are presented in Table 5.

Fig. 6 shows that the removal rate for heavy metals was gradually reduced with the repair time. The electro-kinetics removal rate for heavy metals was faster after 5 days than it was after 15 days. As the $\mathrm{H}^{+}$ions increased with the passage of
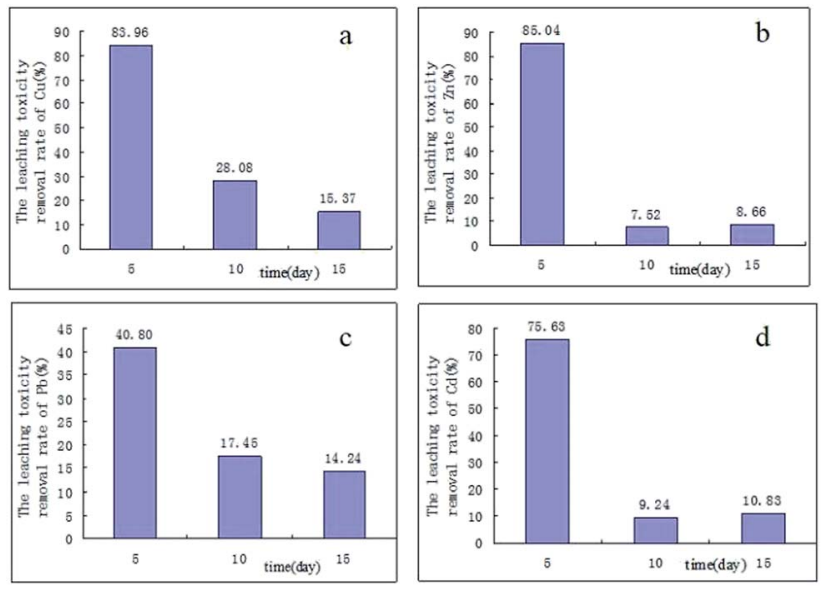

Fig. 6 The effect on time for leaching toxicity removal rate. 
Table 6 Analysis of range results table of $\mathrm{Cu}, \mathrm{Zn}, \mathrm{Pb}, \mathrm{Cd}$

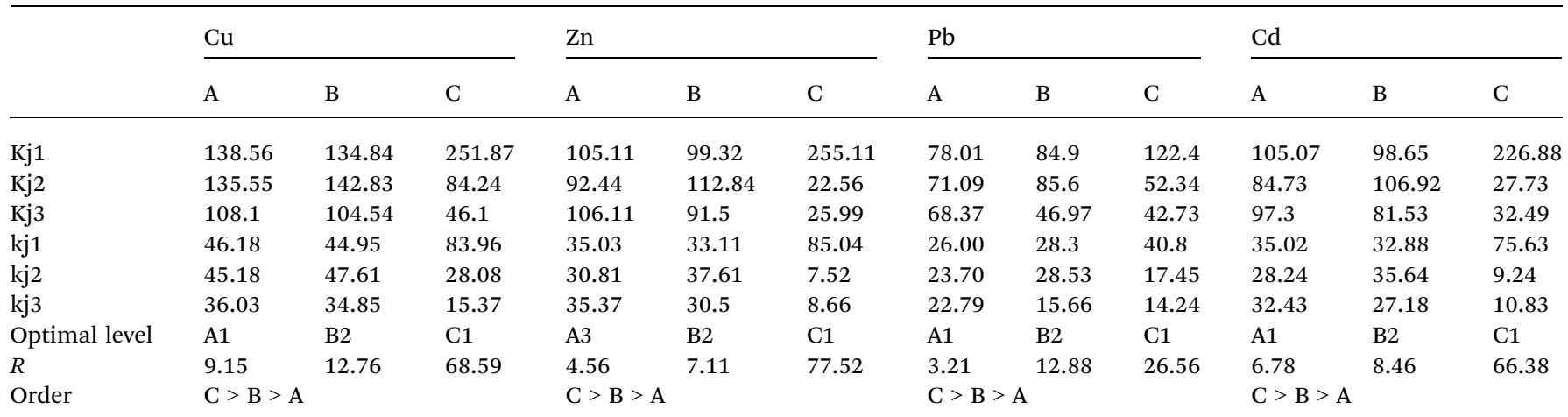

time, the $\mathrm{pH}$ of the cathode and anode decreased. Therefore, the increased content of $\mathrm{H}^{+}$ions reacted with the hydroxide precipitated heavy metals and caused them to release. Hence the heavy metals concentration in solution increased with time and resulted in a declining removal rate. The migration process for $\mathrm{H}^{+}$is similar to the selection of the sample area; heavy metal released process is combined with solid and liquid phases. Heavy metals in fly ash with different activities resulted different heavy metal removal rate of the heavy metal was different. The release of heavy metals in fly ash follows the following five processes: ${ }^{27}$

(1) $\mathrm{H}^{+}$in the sample area diffuses through the diffusion layer to the surface of the fly ash particles.

(2) The solid residues are leached with electrolysis reactions, and $\mathrm{H}^{+}$penetrates into the particles through the solid residue.

(3) $\mathrm{H}^{+}$has chemical reaction with the active material in the fly ash particles, and the heavy metal in the solid residues is released.

(4) The unreacted $\mathrm{H}^{+}$continues to react chemically with the active substances in the fly ash particles, and the heavy metal ions released in the third step enter into the solid residues by diffusion;

(5) The fly ash heavy metal ions from the fourth step further diffuse from the solid surface outward.

Then the heavy metals are removed from the fly ash.

It can be seen from Table 6 that, the range of the three factors for $\mathrm{Cu}$ was $R_{\mathrm{A}}=9.15, R_{\mathrm{B}}=12.76$, and $R_{\mathrm{C}}=68.59$. The range of the three factors for $\mathrm{Zn}$ was $R_{\mathrm{A}}=4.556666667, R_{\mathrm{B}}=$ 7.11, and $R_{\mathrm{C}}=77.52$. The range of the three factors for $\mathrm{Pb}$ was $R_{\mathrm{A}}=3.21, R_{\mathrm{B}}=12.88$, and $R_{\mathrm{C}}=26.56$; and the range of the three factors for Cd was $R_{\mathrm{A}}=6.78, R_{\mathrm{B}}=8.46$, and $R_{\mathrm{C}}=$ 66.38. The results for the ranges of the three factors of the four elements suggested that the most influential factor was C. In general, every factor has an impact on the removal rate of heavy metals but repair time was best followed by the voltage gradient and the particle dose ratio. A1, B2 and C1 were the optimum factor levels for the removal of heavy metals with the optimal combination of A1B2C1. Therefore, it is concluded that the best removal rate were obtained with a $5 \%$ dosing ratio, a voltage gradient of $9 \mathrm{~V}$ and 5 days of repair time.

\section{Conclusions}

During the electric experiment, the $\mathrm{H}^{+}$that was produced by the anode electrolysis of water migrated to the sample area and reacted with the heavy metal compound, and the heavy metal ions were released. The heavy metal ions migrated to the cathode under the action of the electric field, which removed the heavy metal in the fly ash. Proper handling of high concentrations of heavy metals $(\mathrm{Cu}, \mathrm{Zn}, \mathrm{Pb}$ and $\mathrm{Cd})$ is necessary to protect the environment. In the present scheme, it can be seen from the table of XRF results that the heavy metals in MSWI fly ash exist mainly in the form of oxides, and that the content of heavy metals in fly ash is much higher than the environmental soil (GB15618-2008) of residential land secondary standards. The samples were treated using a threedimensional electrode with graphite particles as a third electrode for removing heavy metals. In the single-factor orthogonal experiment, the best removal rate for heavy metals is observed in a graphite electrode having the dimensions of $6 \times 6 \mathrm{~mm}$. In contrast, the best results in the multi-factor orthogonal experiments, which were based on three factors including the particle electrode ratio, voltage gradient and repair time, are obtained after five days repair time with a voltage gradient of $9 \mathrm{~V}$ and a $5 \%$ dose ratio for the particle electrode. The removal rates for $\mathrm{Cu}$, $\mathrm{Zn}, \mathrm{Pb}$ and $\mathrm{Cd}$ were $89.05 \%, 90.51 \%, 50.38 \%$ and $82.56 \%$, respectively, and they are greatly improved compared to electrokinetic remediation with two-dimensional electrodes. Thus, I think the electro-kinetic remediation with three-dimensional electrodes has a certain degree of desirability and reference for the electro-kinetic remediation of heavy metals.

\section{Notes and references}

1 H. Y. Xu, Development Analysis on Treatment Technology of Domestic Refuse Incineration, China Environmental Protection Industry, 2010, vol. 9, pp. 10-15.

2 Q. Zhang and H. Y. Xu, Status and Development Suggestion of Incineration Technology of Domestic Garbage, Environ. Eng., 2012, 2, 79-81.

3 M. Z. Wang, The Feasibility Analysis of Garbage Treatment, Urban Development Studies, 2013, vol. 2, pp. 138-140. 
4 Y. M. Zhang, X. B. Shang, K. M. Li, C. S. Zhang, et al., Technologies status and management strategies of municipal solid waste disposal in China, Ecology and Environmental Sciences, 2011, 2, 389-396.

5 D. Qian, Study on Incineration of Municipal Waste and the Pollution Control, J. Anhui Agric. Sci., 2015, 9, 261-263.

6 M. D. Bovea, V. Ibááñez-Forés, A. Gallardo, et al., Hydrogarnet: Environmental assessment of alternative municipal solid waste management strategies. A Spanish case study, Waste Manag., 2010, 11, 2383-2395.

7 A. Umberto, Process and technological aspects of municipal solid waste gasification. A review, Waste Manag., 2012, 32, 625-639.

8 P. Su, G. H. Wang, Y. Z. Liu and Y. C. Yuan, Status quo of the development of incineration technologies for municipal waste, Energy Res. Inf., 2002, 3, 143-149.

9 B. Q. Jiao, X. Peng, D. Y. Li and Y. E. Qiu, A Study on Treating Bathing Wastewater by Electrocoagulation-Flotation, Res. J. Chem. Environ., 2011, 15, 533-539.

10 K. Yuan, H. P. Xiao and X. D. Li, Development and Application of Municipal Solid Waste in Cineration in China, Energy Engineering, 2008, 5, 43-46.

11 M. Ahmaruzzaman, Review on the Utilization of Fly Ash, Prog. Energy Combust. Sci., 2010, 36, 327-363.

12 P. Martin, T. Michal, K. Petr and B. Ladislav, Waste Incineration with Production of Clean and Reliable Energy, Clean Technol. Environ. Policy, 2011, 13, 595-605.

13 J. Virkutyte, M. Sillanpää and P. Latostenmaa, Electrokinetic Soil Remediation-critical Overview, Sci. Total Environ., 2002, 289, 97-121.

14 D. M. Zhou, C. F. Deng and L. Cang, Electrokinetic Remediation of $\mathrm{A} \mathrm{Cu}$ Contaminated Red Soil by Conditioning Catholyte $\mathrm{pH}$ with Different Enhancing Chemical Reagents, Chemosphere, 2004, 56, 265-273.

15 A. Altin and M. Degirmenci, Lead(II) Removal from Natural Soils by Enhanced Electrokinetic Remediation, Sci. Total Environ., 2005, 337, 1-10.

16 J. R. Backhurst, J. M. Coulson, F. J. Goodridge, et al., A preliminary investigation of fluidized bed electrodes, $J$. Electrochem. Soc., 1969, 116, 1600-1607.
17 H. Z. Ma and B. Wang, Electrochemical pilot-scale plant for oil field produced wastewater by $\mathrm{M} / \mathrm{C} / \mathrm{Fe}$ electrode for injection, J. Hazard. Mater., 2006, 132, 237-243.

18 Y. Xiong, C. He, H. T. Karlsson and X. Zhu, Performance of three phase three-dimensional electrode reactor for the reduction of COD in simulated wastewater containing phenol, Chemosphere, 2003, 50, 131-136.

19 J. Zhang, X. Q. Ran, J. W. Fan and X. H. Liu, Research Progresses in Treatment of Wastewater Using ThreeDimensional Electrode, Sichuan Environment, 2011, 3, 119122.

20 J. O. M. Bockris and J. Kim, Effect of contact resistance between particles on the current distribution in a packed bed electrode, J. Appl. Electrochem., 1997, 27, 890-901.

21 S. F. Zhang and X. E. Hu, Treatment of Lead-containing Wastewater by Three-Dimensional Electrode Electrolysis Method, Ind. Water Treat., 2012, 4, 42-45.

$22 \mathrm{H}$. Xuekui and W. Sanfan, Treatment of Waste Water Containing $\mathrm{Cu}^{2+}$ by the Three-Dimensional Electrodes Method, Journal of Lanzhou Railway Institute, 2002, 06, 96-98.

23 G. F. Lv, D. C. Wu and R. W. Fu, Performance of Carbon Aerogels Particle Electrodes for the Aqueous Phase Electrocatalytic Oxidation of Simulated Phenol Wastewaters, $J$. Hazard. Mater., 2009, 165, 961-966.

24 P. Zou, Q. Wang and J. J. Hu, Study on flue gas desulfurization with packed bed three-dimensional electrode of granular activated carbon, Environ. Pollut. Control, 2006, 03, 191-193.

25 K. Vann, S. Musson and T. Townsend, Evaluation of a modified TCLP methodology for RCRA toxicity characterization of computer CPUs, J. Hazard. Mater., 2006, 129, 101-109.

26 B. Hou, K. Zhu, J. Lu and Y. F. Zhao, Experimental Study on Electrokinetic Remediation of Nickel-Polluted Soil, J. AgroEnviron. Sci., 2008, 6, 2195-2199.

27 S. Kuen, Y. Kung, C. Chin and J. Chang, Effect of chlorides on emissions of toxic compounds in waste incineration: study on partitioning characteristics of heavy metal, Chemosphere, 1999, 38, 1833-1849. 